\title{
Novel hydroxybutyl chitosan nanoparticles for siRNA delivery targeting tissue factor inhibits proliferation and induces apoptosis in human vascular smooth muscle cells
}

\author{
KANG WAN ${ }^{1 *}$, JIAN LI $^{1 *}$, DAN LI ${ }^{1}$, JUNHUA GE$^{1}$, YUNLONG WANG ${ }^{2}$, XUEXUN LI $^{3}$, \\ YONGFANG GUO ${ }^{1}$, JUNJIE GUO ${ }^{1}$, MIN LENG ${ }^{1}$, PAN WANG $^{1}$ and YI AN $^{1}$ \\ ${ }^{1}$ Department of Cardiology, The Affiliated Hospital of Qingdao University; ${ }^{2}$ Department of Gout, \\ The Affiliated Hospital of Qingdao University, Shandong Provincial Key Laboratory of Metabolic Diseases, Qingdao, \\ Shandong 266003; ${ }^{3}$ Department of Cardiology, Yantai Yuhuangding Hospital Affiliated to Qingdao University, \\ Yantai, Shandong 266000, P.R. China
}

Received December 22, 2014; Accepted September 16, 2015

DOI: $10.3892 / \mathrm{mmr} .2015 .4461$

\begin{abstract}
Chitosan, a polysaccharide isolated from shrimp and other crustacean shells, has been widely investigated for DNA and siRNA delivery. Despite substantial effort having been made to improve chitosan as a non-viral gene delivery vector, the application is severely limited by its poor solubility under physiological conditions. Hydroxybutyl chitosan (HBC), a modified chitosan, is soluble under neutral conditions. Tissue factor (TF) is involved in the pathogenesis of cardiovascular diseases by promoting thrombus formation and inducing the migration and proliferation of vascular smooth muscle cells. Targeting TF is an attractive therapeutic strategy for cardiovascular diseases. In the present study, the use of HBC for the transfer of TF-siRNAs into human umbilical vein smooth muscle cells (HUVSMCs) was investigated, and the effects of TF knockdown on cell proliferation and apoptosis were examined. HBC/siRNA nanoparticles were produced by mixing $\mathrm{HBC}$ and siRNA solutions with the assistance of tripolyphosphate buffer. The transfection efficiency with these nanoparticles was $74 \pm 2.5 \%$, which was determined using a fluorescence-labeled siRNA under fluorescence microscopy. The delivery of HBC/TF-siRNA resulted in reductions in the production of cellular and soluble TF protein in HUVMSCs, which were measured using western blotting and enzyme-linked immunosorbent assay, respectively. TF knockdown led to
\end{abstract}

Correspondence to: Dr Jian Li, Department of Cardiology, The Affiliated Hospital of Qingdao University, 16 Jiangsu Road, Shinan, Qingdao, Shandong 266003, P.R. China

E-mail: jianliqingdao@gmail.com

*Contributed equally

Key words: gene delivery, hydroxybutyl chitosan, cardiovascular disease, tissue factor, siRNA, vascular smooth muscle cell, cell proliferation, cell apoptosis inhibited cell proliferation, as assessed using a Cell Counting Kit-8 assay, and increased cell apoptosis, determined using Annexin V-fluorescein isothiocyanate staining. These findings suggested that HBC may be a promising vector for siRNA delivery, and that in vivo $\mathrm{HBC} / \mathrm{siRNA}$ nanoparticle delivery targeting TF may be a potential option for the treatment of cardiovascular diseases, which warrants further investigation.

\section{Introduction}

Chitosan, a linear polysaccharide isolated from shrimp and other crustacean shells, possesses low toxicicity, is biodegradable and exhibits favorable biocompatible properties, rendering it a promising material for biomedical applications (1-3). Notably, several studies have investigated the potential of chitosan for drug delivery, bio-coating and the transferring of genetic materials (1-6). However, one setback, which limits the use of chitosan, is its insolubility under neutral conditions (3). Previously, a modified chitosan, namely hydroxybutyl chitosan (HBC), has been developed and exhibits advantages over the parental chitosan. HBC is prepared by the conjugation of hydroxybutyl groups to the hydroxyl and amino reactive sites of chitosan (7). This change confers the polymer solubility under neutral conditions, whilst maintaining low toxicity and retaining its biodegradable and appreciable biocompatible properties (7-9).

Tissue factor (TF) is an essential cofactor in the initiation of coagulation (10). It is constitutively expressed and can be upregulated by various stimuli, including platelet-derived growth factor (PDGF) in vascular smooth muscle cells $(11,12)$. In response to cytokines and growth factors, endothelial cells, monocytes and macrophages also produce TF (13-19). Two forms of TF, membrane-bound and soluble TF, have been identified $(10,12,20-22)$. TF has been implicated in the pathogenesis of cardiovascular diseases, including hypertension, atherosclerosis, acute coronary syndrome and restenosis following percutaneous coronary intervention, by promoting thrombus formation and inducing the migration and proliferation of vascular smooth muscle cells (23-29). 
Therefore, targeting TF has been suggested as an attractive strategy for the treatment of cardiovascular diseases (30). In the present study, the use of HBC for the transfer of siRNAs into primary human umbilical vein vascular smooth muscle cells (HUVSMCs) targeting TF was investigated, and the efficiency of HBC-mediated siRNA transfer was examined, as were the effects of TF knockdown on HUVSMC proliferation and apoptosis.

\section{Materials and methods}

siRNAs. All siRNAs were purchased from Invitrogen (Thermo Fisher Scientific, Inc., Waltham, MA, USA). A fluorescent FAM-labeled siRNA was used to examine transfer efficiency. An siRNA targeting human TF was designed, according to the published human TF cDNA sequence (gene accession number: M16553.1; GenBank; http://www.ncbi.nlm.nih. gov/nuccore/M16553.1). The sequence of the antisense strand was 5'-AUUUGUAGUGCCUGAAGCGCTT-3'. A scrambled RNA sequence was used as control.

Preparation of HBC/siRNA nanoparticles. HBC/siRNA nanoparticles were prepared as follows: The HBC solution (1 $\mathrm{mg} / \mathrm{ml}$ ) was made by dissolving HBC (molecular weight: 130-160 kDa; degree of deacetylation: $86 \%$ ) provided by the Ocean University of China (Qingdao, China) in $0.2 \mathrm{M}$ acetic acid (pH 5.5; Sigma-Aldrich, , St. Louis, MO, USA). The siRNA (final concentration, $20 \mu \mathrm{mol} / \mathrm{l}$ ) was mixed with tripolyphosphate (TPP) solution $(0.5 \mathrm{mg} / \mathrm{ml}$; Sigma-Aldrich) under magnetic stirring. HBC/siRNA nanoparticles were then produced by slowly adding $1 \mathrm{ml}$ of the siRNA/TPP solution to $3 \mathrm{ml}$ of the HBC solution with stirring for $30 \mathrm{~min}$. The loading efficiency of the siRNA within HBC was determined as follows: The HBC/siRNA mixture, prepared as above, was centrifuged at $13,000 \times \mathrm{g}$ for $15 \mathrm{~min}$, following which the supernatant was collected and the siRNA content in the supernatant was determined by measuring the absorbance at $260 \mathrm{~nm}$ using a spectrophotometer (UV-1100; Shimadzu Corporation, Kyoto, Japan). The loading efficiency was calculated as a percentage, as follows: Total siRNA used - free siRNA remaining in the supernatant) / total siRNA used.

Cell culture and siRNA transfer. Primary HUVSMCs (Bai Li Biological Technology, Shanghai, China) were maintained at $37^{\circ} \mathrm{C}$ in RPMI-1640 medium (Gibco, Thermo Fisher Scientific, Inc.) supplemented with $10 \%$ fetal bovine serum (FBS, Gibco; Thermo Fisher Scientific, Inc.), $100 \mathrm{U} / \mathrm{ml}$ penicillin and $0.1 \mathrm{mg} / \mathrm{ml}$ streptomycin (Gibco; Thermo Fisher Scientific, Inc.). Cells were used between passages four and nine. For siRNA transfer, the cells were detached with $0.25 \%$ trypsin (Thermo Fisher Scientific, Inc.), seeded on 24-well plates $\left(1 \times 10^{5}\right.$ cells/well) and incubated overnight at $37^{\circ} \mathrm{C}$ in complete RPMI-1640 medium. Following replacing of the medium with $250 \mu$ l Opti-MEM serum-free medium (Gibco; Thermo Fisher Scientific, Inc.), HBC/siRNA nanoparticle solution was added (siRNA final concentration, $200 \mathrm{nM}$ ). The cells were incubated at $37^{\circ} \mathrm{C}$ for $4 \mathrm{~h}$ to allow for siRNA uptake. Following incubation, the medium containing nanoparticles was replaced with fresh complete RPMI 1640 medium and the cells were maintained in culture and assayed at different time points (24, 48 and $72 \mathrm{~h})$, as indicated. A total of $24 \mathrm{~h}$ post-transfection, five high-power fields were randomly selected under a fluorescence microscope (Nikon E600; Nikon Corporation, Tokyo, Japan), and total fluorescent cells in each field were counted. The percentage of average fluorescent cells over average total cells from the five fields was used to determine the transfection efficiency

TF protein measurement. As HUVSMCs express minimal basal TF, the cells examined in the present study were treated with PDGF-BB to enhance the production of TF protein. PDGF-BB (10 ng/ml, Sigma-Aldrich) was added to the cell culture $24 \mathrm{~h}$ following HBC/siRNA transfection. Inhibition of the PDGF-BB-induced expression of TF by TF-siRNA was then determined $48 \mathrm{~h}$ following siRNA transfection. The levels of soluble and cellular TF protein were measured using an enzyme-linked immunosorbent assay (ELISA) and western blotting, respectively. For the soluble TF assay, the cultured conditioned medium was collected, centrifuged at $10,000 \mathrm{x} \mathrm{g}$ for $10 \mathrm{~min}$ and the level of soluble TF in the medium was measured using a Human F3/Tissue Factor ELISA kit (cat. no. RAB0642-1KT; Sigma-Aldrich), according to the manufacturer's protocol. For western blotting, total protein was extracted using radioimmunoprecipitation assay lysis buffer (Sigma-Aldrich) and protein concentration was determined using a bicinchoninic acid assay (Pierce Biotechnology, Inc., Rockford, IL, USA), according to the manufacturer's protocol. The proteins $(50 \mu \mathrm{g})$ were separated by $10 \%$ SDS-PAGE (Thermo Fisher Scientific, Inc.) and electrically transferred onto nitrocellulose membrane (Thermo Fisher Scientific, Inc.). The membrane was blocked with phosphate-buffered saline $(\mathrm{pH} 7.5)$ with $0.1 \%$ Tween-20 (PBST; Sigma-Aldrich) and $10 \%$ non-fat milk for $1 \mathrm{~h}$ at room temperature, and incubated overnight at $4^{\circ} \mathrm{C}$ with mouse anti-human TF monoclonal antibody $(1: 1,000$; cat. no. ab17375; Abcam, Cambridge, MA, USA), followed by three washes with PBST. The membrane was then incubated with a horseradish peroxidase (HRP)-conjugated goat anti-mouse secondary antibody (1:5,000; cat. no. ab6789; Abcam) at room temperature for $1 \mathrm{~h}$. Following three washes with PBST, the specific TF band was visualized using an ECL detection kit (Abcam). Glyceraldehyde 3-phosphate dehydrogenase (GAPDH) on the same membrane was probed with a mouse anti-human GAPDH monoclonal antibody (1:5,000; cat. no. ab9484; Abcam) as done with TF. Densitometric analysis was performed, and relative quantitation of TF normalized to GAPDH was determined using Image $\mathbf{J}$ software (National Institutes of Health, Bethesda, MA, USA).

Cell proliferation assay. HUVSMC proliferation was assessed $48 \mathrm{~h}$ following the addition of the $\mathrm{HBC} / \mathrm{siRNA}$ nanoparticles using a Cell Counting Kit-8 (CCK-8; Sigma-Aldrich), according to the manufacturer's protocol. Briefly, the culture medium was replaced with fresh complete RPMI 1640 medium (without phenol red) containing 10\% CCK-8 reagent. Following culture for $24 \mathrm{~h}, 200 \mu \mathrm{l}$ of supernatant from each well was transferred to a 96-well plate for the measurement of optical density (OD) at $450 \mathrm{~nm}\left(\mathrm{OD}_{450}\right)$ using a microplate reader (model 550; Bio-Rad Laboratories, Inc., Hercules, CA, USA). 

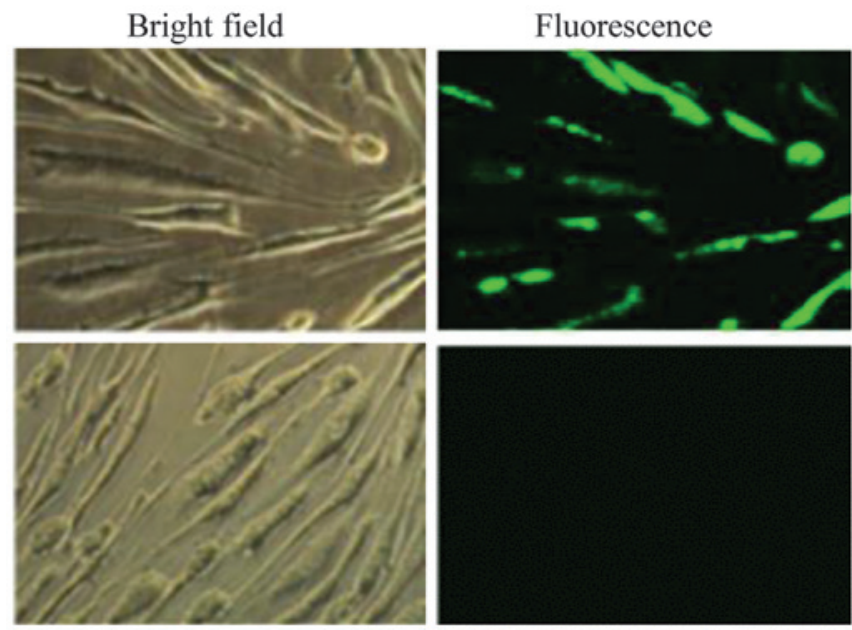

Figure 1. Transfection of HUVSMCs with HBC/siRNA nanoparticles. Green fluorescence dye FAM-labeled siRNAs were mixed with HBC solution to prepare HBC/siRNA nanoparticles. These nanoparticles were used to transfect HUVSMCs, and the cells transfected with HBC/FAM-siRNA exhibited green fluorescence (top panel). The scramble-siRNA treated cells exhibited no fluorescence (bottom panel), as observed under fluorescence microscopy $24 \mathrm{~h}$ following transfection. This method resulted in a high transfection efficiency of $74 \%$ in the HUVSMCs. HUVSMC, human umbilical vein smooth muscle cells; HBC, hydroxybutyl chitosan. Magnification, x40.

Cell apoptosis assay. Apoptosis of the HUVSMCs was assayed using an Annexin V-fluorescein isothiocyanate (FITC) Apoptosis Detection kit (Solarbio Science \& Technology Co., Ltd., Beijing, China), according to the manufacturer's protocol. Briefly, $72 \mathrm{~h}$ after siRNA transfection, the cells were detached and resuspended in binding buffer (Solarbio Science \& Technology Co., Ltd.) at a density of $1 \times 10^{6} / \mathrm{ml}$. Subsequently, $100 \mu \mathrm{l}$ of the cell suspension was incubated with $5 \mu \mathrm{l}$ Annexin V-FITC and $10 \mu \mathrm{l}$ propidium iodide at $4^{\circ} \mathrm{C}$ for $15 \mathrm{~min}$ in the dark. Following a single wash with PBS, the Annexin V-FITC-positive cells (apoptotic cells) were analyzed using a FACSCalibur Flow Cytometer (BD Biosciences, Franklin Lakes, NJ, USA).

Statistical analysis. Data are expressed as the mean \pm standard deviation. Statistical analyses of the differences were performed using one way analysis of variance. Comparisons between two groups were performed using the least-significant difference test. SPSS 17.0 (SPSS, Inc., Chicago, IL, USA) and PRISM software (GraphPad Software, Inc., La Jolla, CA, USA) were used for statistical analyses and plotting. $\mathrm{P}<0.05$ was considered to indicate a statistically significant difference.

\section{Results}

Preparation of HBC siRNA nanoparticles and siRNA transfer. HBC and siRNA solutions were mixed and stirred to form HBC/siRNA nanoparticles. TPP was used as a cross-linker to further stabilize the nanoparticle. This method resulted in an siRNA loading efficiency of $93.4 \pm 0.7 \%$ within HBC. Treatment of the HUVSMCs with nanoparticles, which were formed by mixing HBC and FAM-labeled siRNAs, showed green fluorescence in the transfected cells, as observed under fluorescence microscopy (Fig. 1). Counting of the numbers of fluorescent and total cells revealed a $74 \pm 2.5 \%$ transfection efficiency.

Knockdown of TF by HBC/TF-siRNA nanoparticles in HUVSMCs. Inhibition of the PDGF-BB-induced expression

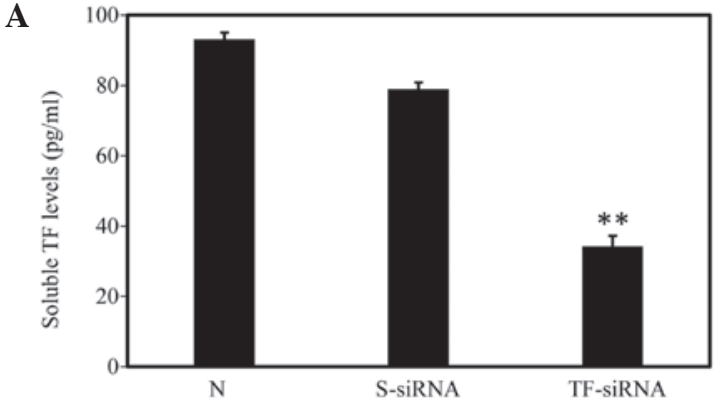

B

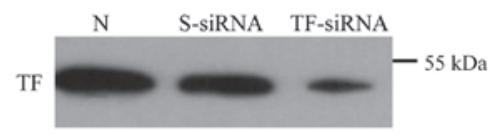

GAPDH

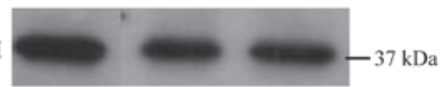

C

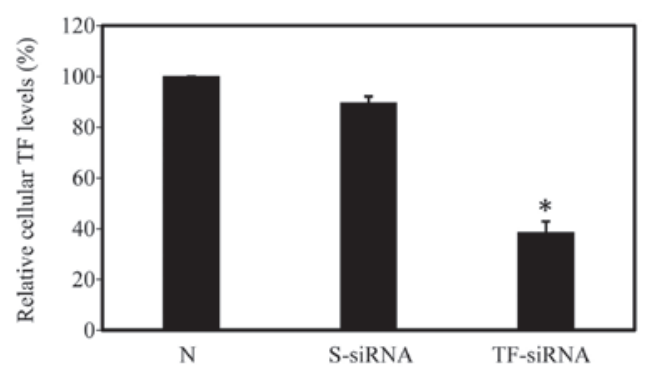

Figure 2. TF protein production is inhibited in HUVSMCs following HBC/TF-siRNA transfection. (A) Enzyme-linked immunosorbent assay results showed that the production of soluble TF induced by PDGF-BB in HUVSMCs was significantly reduced in the TF-siRNA cells, compared with the scramble siRNA cells. (B) Representative western blot of cellular TF revealed that TF-siRNA, but not scrambled-siRNA transfection, significantly suppressed the protein expression of cellular TF induced by PDGF-BB. (C) Summarized levels of cellular TF, normalized against GAPDH, were plotted. The cellular levels of TF in the non-transfected cells were arbitrarily set at $100 \%$. Data are expressed as the mean \pm standard deviation. ${ }^{*} \mathrm{P}<0.05$ and ${ }^{* *} \mathrm{P}<0.01$, compared with the non-transfected cells. TF, tissue factor; HUVSMC, human umbilical vein smooth muscle cell; HBC, hydroxybutyl chitosan; PDGF-BB, platelet-derived growth factor; N, non-transfected; S-siRNA, scrambled siRNA-transfected; TF-siRNA, TF-siRNA-transfected. 


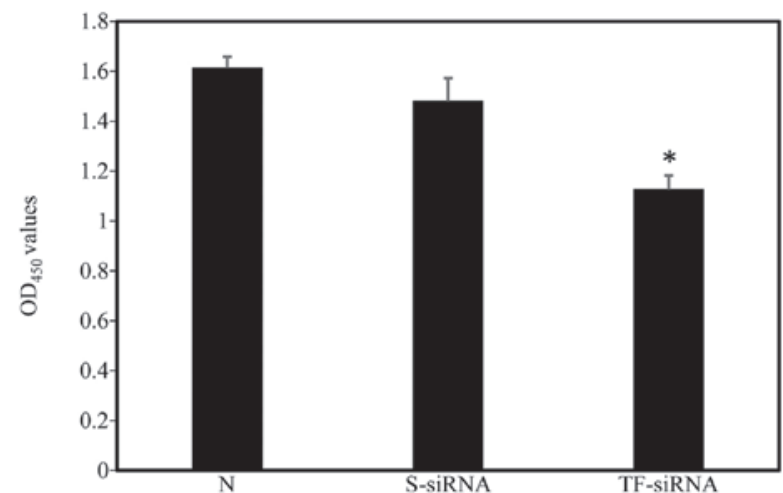

Figure 3. TF knockdown inhibits the proliferation of HUVSMCs. Cell proliferation was assessed $48 \mathrm{~h}$ following HBC/siRNA transfection using a Cell Counting Kit-8. The results revealed that transfection with TF-siRNA, but not scrambled-siRNA resulted in significant inhibition of HUVSMC proliferation. Data are expressed as the mean \pm standard deviation. ${ }^{.} \mathrm{P}<0.05$, compared with the non-transfected cells. TF, tissue factor; HUVSMC, human umbilical vein smooth muscle cell; HBC, hydroxybutyl chitosan; $\mathrm{N}$, non-transfected; S-siRNA, scrambled siRNA-transfected; TF-siRNA, TF-siRNA-transfected; OD, optical density.

of TF by TF-siRNA in the HUVSMCs was determined $48 \mathrm{~h}$ following siRNA transfection. The ELISA results showed that the level of soluble TF in the TF-siRNA-transfected cells was $34.2 \pm 1.8 \mathrm{pg} / \mathrm{ml}$, which was significantly lower than the level in the non-transfected cells $(93.1 \pm 2.0 \mathrm{pg} / \mathrm{ml} ; \mathrm{n}=12 ; \mathrm{P}<0.01)$. In the cells transfected with scrambled siRNA, the level of soluble TF was $79.0 \pm 3.0 \mathrm{pg} / \mathrm{ml}$, which was not significantly different from that of the untreated cells (Fig. 2A). Western blotting revealed that the relative cellular level of TF in the TF-siRNA-transfected cells was $38.5 \pm 2.6 \%$ of that in the non-transfected cells $(\mathrm{n}=12 ; \mathrm{P}<0.05)$. By contrast, scrambled siRNA transfection caused no significant reduction in the level of cellular TF (Fig. 2B and C).

TF knockdown inhibits HUVSMC proliferation. HUVSMC proliferation was measured $48 \mathrm{~h}$ following siRNA transfection using a CCK-8 kit. No significant differences were observed between the $\mathrm{OD}_{450}$ values of the non-transfected and scrambled siRNA-treated HUVSMCs. By contrast, TF-siRNA transfection significantly inhibited HUVMSC proliferation (Fig. 3; n=4).

TF knockdown increases HUVSMC apoptosis. HUVMSC apoptosis was assayed using Annexin V staining and flow cytometric analysis $72 \mathrm{~h}$ following siRNA delivery. As shown in Fig. 4, cell apoptotic rates were $5.1 \pm 0.71$ and $7.73 \pm 0.87 \%$ in the non-transfected and HBC/scrambled siRNA nanoparticle-transfected cells, respectively. Statistical analysis demonstrated no significant difference between the levels of apoptosis in these two groups. However, the apoptotic rate in the TF-knockdown HUVMSCs was $42.25 \pm 1.82 \%$, which was significantly higher than those observed in the non-transfected and scrambled siRNA-transfected cells $(\mathrm{P}<0.05 ; \mathrm{n}=4)$.

\section{Discussion}

Despite significant efforts that have been made to improve chitosan as a non-viral gene delivery vector, the application is significantly limited by its poor solubility under
A

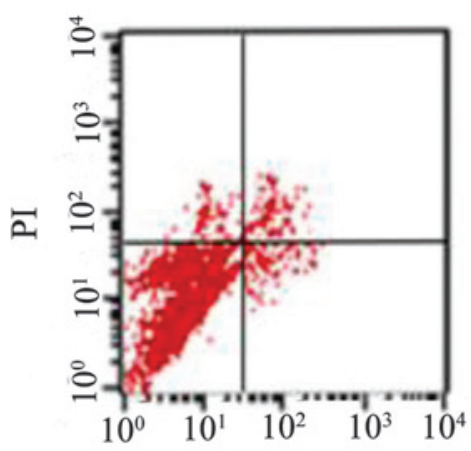

Annexin V-FITC
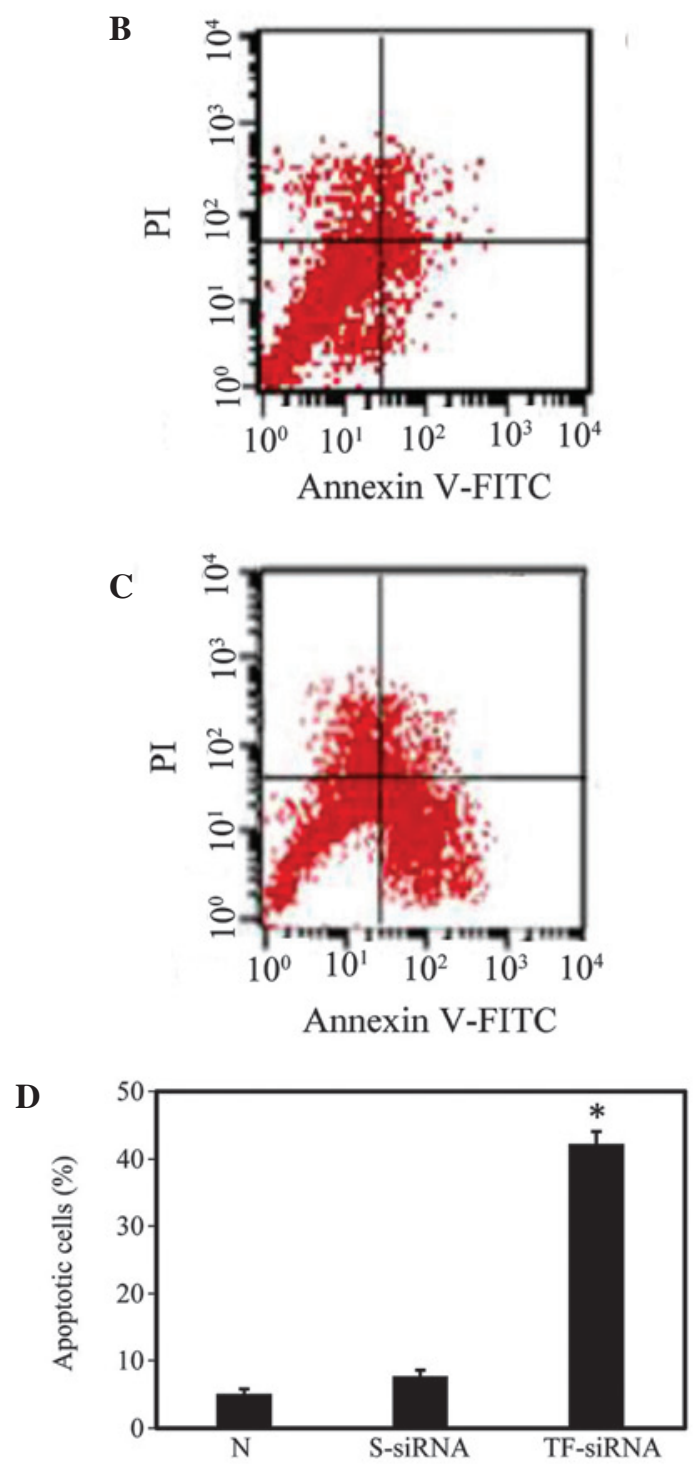

Figure 4. TF-siRNA transfection enhances human umbilical vein smooth muscle cell apoptosis. Cell apoptosis was assayed using Annexin V-FITC staining and flow cytometric analysis $72 \mathrm{~h}$ following transfection. The TF-siRNA transfected cells underwent a significantly higher rate of apoptosis, compared with non-transfected cells. By contrast, the scrambled siRNA-transfected cells exhibited similar levels of apoptosis as the non-transfected cells. Representative dot plots of flow cytometry in the (A) non-transfected cells; (B) scrambled siRNA-transfected cells and (C) TF-siRNA transfected cells). (D) Summarized data on cell apoptosis are shown. Data are expressed as the mean \pm standard deviation. "P<0.05, compared with the non-transfected cells. TF, tissue factor; N, non-transfected; S-siRNA, scrambled siRNA-transfected; TF-siRNA, TF-siRNA-transfected; PI, propidium iodide; FITC, fluorescein isothiocyanate. 
physiological conditions (31). HBC, a soluble derivative of chitosan under neutral conditions, has been investigated as a scaffold for tissue engineering $(32,33)$, however its use as a gene delivery carrier remains to be fully elucidated. In the present study, HBC was investigated as a vehicle for siRNA delivery targeting TF in HUVSMCs. HBC/siRNA nanoparticles were produced by mixing $\mathrm{HBC}$ and siRNA solutions with TPP as a cross-linker. This resulted in $>90 \%$ of the siRNAs being loaded within HBC. Furthermore, treatment of the HUVSMCs with the HBC/fluorescence-siRNA nanoparticles resulted in a transfection efficiency of $\sim 74 \%$. These results validated that $\mathrm{HBC}$ was a promising vehicle for siRNA delivery.

siRNA binds an mRNA sequence through complementarity, which leads to the cleavage of target mRNA and, eventually, the inhibition of gene expression (34). siRNA has been investigated extensively for its therapeutic potential, for example in the use of siRNAs to silence tumor genes, or genes in which overexpression has been associated with disease $(35,36)$. TF is involved in thrombus formation and stimulates the migration and proliferation of vascular smooth muscle cells, contributing to the pathogenesis of cardiovascular diseases (23-29). As a consequence, inhibition of the action of TF has been suggested as an attractive therapeutic approach for cardiovascular diseases (30). Following confirmation of effective siRNA delivery with $\mathrm{HBC}$, the present study assessed whether HBC/TF-siRNA nanoparticles were able to inhibit the expression of TF in HUVSMCs, and examined the effect of TF knockdown on cell proliferation and apoptosis. The results showed that HBC-mediated TF-siRNA transfer suppressed the production of cellular and soluble TF, which led to the significant inhibition of cell proliferation and increase of cell apoptosis.

In conclusion, the present study demonstrated that HBC can be successfully applied for siRNA loading. HBC/siRNA nanoparticles mediated high siRNA transfection efficiency in HUVMSCs, and treatment of HUVSMCs with HBC/TF-siRNA nanoparticles inhibited the protein expression of TF, which led to decreased cell proliferation and enhanced cell apoptosis. These findings suggested that $\mathrm{HBC}$ may be a promising vector for siRNA delivery, and that in vivo HBC/siRNA nanoparticle delivery targeting $\mathrm{TF}$ is a potential therapeutic option for the treatment of cardiovascular diseases, warranting further investigation.

\section{Acknowledgements}

This study was supported by the National Natural Science Foundation of China (grant. no. 81200202); the Shandong Province Natural Science Foundation, China (grant. no. ZR2010HM081) and the China Postdoctoral Science Foundation (grant. no. 2012M511462).

\section{References}

1. Illum L: Chitosan and its use as a pharmaceutical excipient. Pharm Res 15: 1326-1331, 1998.

2. Felt $\mathrm{O}$, Buri $\mathrm{P}$ and Gurny R: Chitosan: A unique polysaccharide for drug delivery. Drug Dev Ind Pharm 24: 979-993, 1998.

3. Kumar MN, Muzzarelli RA, Muzzarelli C, Sashiwa H and Domb AJ: Chitosan chemistry and pharmaceutical perspectives. Chem Rev 104: 6017-6084, 2004.
4. Nafee N, Taetz S, Schneider M, Schaefer UF and Lehr CM: Chitosan-coated PLGA nanoparticles for DNA/RNA delivery: Effect of the formulation parameters on complexation and transfection of antisense oligonucleotides. Nanomedicine 3: 173-183, 2007.

5. Köping-Höggård M, Tubulekas I, Guan H, Edwards K, Nilsson M, Vărum KM and Artursson P: Chitosan as a nonviral gene delivery system. Structure-property relationships and characteristics compared with polyethylenimine in vitro and after lung administration in vivo. Gene Ther 8: 1108-1121, 2001.

6. Katas $\mathrm{H}$ and Alpar HO: Development and characterisation of chitosan nanoparticles for siRNA delivery. J Control Release 115: 216-225, 2006

7. Dang JM, Sun DD, Shin-Ya Y, Sieber AN, Kostuik JP and Leong KW: Temperature-responsive hydroxybutyl chitosan for the culture of mesenchymal stem cells and intervertebral disk cells. Biomaterials 27: 406-418, 2006.

8. Molinaro G, Leroux JC, Damas J and Adam A: Biocompatibility of thermosensitive chitosan-based hydrogels: An in vivo experimental approach to injectable biomaterials. Biomaterials 23: 2717-2722, 2002

9. Wei CZ, Hou CL, Gu QS, Jiang LX, Zhu B and Sheng AL: A thermosensitive chitosan-based hydrogel barrier for post-operative adhesions' prevention. Biomaterials 30: 5534-5540, 2009.

10. Mackman N, Morrissey JH, Fowler B and Edgington TS: Complete sequence of the human tissue factor gene, a highly regulated cellular receptor that initiates the coagulation protease cascade. Biochemistry 28: 1755-1762, 1989.

11. Wilcox JN, Smith KM, Schwartz SM and Gordon D: Localization of tissue factor in the normal vessel wall and in the atherosclerotic plaque. Proc Natl Acad Sci USA 86: 2839-2843, 1989.

12. Schecter AD, Giesen PL, Taby O, Rosenfield CL, Rossikhina M, Fyfe BS, Kohtz DS, Fallon JT, Nemerson Y and Taubman MB: Tissue factor expression in human arterial smooth muscle cells. $\mathrm{TF}$ is present in three cellular pools after growth factor stimulation. J Clin Invest 100: 2276-2285, 1997.

13. Camera M, Giesen PL, Fallon J, Aufiero BM, Taubman M, Tremoli E and Nemerson Y: Cooperation between VEGF and TNF-alpha is necessary for exposure of active tissue factor on the surface of human endothelial cells. Arterioscler Thromb Vasc Biol 19: 531-537, 1999.

14. Bavendiek U, Libby P, Kilbride M, Reynolds R, Mackman N and Schönbeck U: Induction of tissue factor expression in human endothelial cells by CD40 ligand is mediated via activator protein 1, nuclear factor kappa B and Egr-1. J Biol Chem 277: 25032-25039, 2002.

15. Kawano H, Tsuji H, Nishimura $H$, Kimura $S$, Yano $S$, Ukimura $N$, Kunieda Y, Yoshizumi M, Sugano T, Nakagawa K, et al: Serotonin induces the expression of tissue factor and plasminogen activator inhibitor-1 in cultured rat aortic endothelial cells. Blood 97: 1697-1702, 2001.

16. Cermak J, Key NS, Bach RR, Balla J, Jacob HS and Vercellotti GM: C-reactive protein induces human peripheral blood monocytes to synthesize tissue factor. Blood 82: 513-520, 1993.

17. Mach F, Schönbeck U, Bonnefoy JY, Pober JS and Libby P: Activation of monocyte/macrophage functions related to acute atheroma complication by ligation of CD40: Induction of collagenase, stromelysin and tissue factor. Circulation 96: 396-399, 1997.

18. He M, He X, Xie Q, Chen F and He S: Angiotensin II induces the expression of tissue factor and its mechanism in human monocytes. Thromb Res 117: 579-590, 2006.

19. Wada H, Kaneko T, Wakita Y, Minamikawa K, Nagaya S, Tamaki S, Deguchi K and Shirakawa S: Effect of lipoproteins on tissue factor activity and PAI-II antigen in human monocytes and macrophages. Int J Cardiol 47 (Suppl 1): S21-S25, 1994.

20. Giesen PL, Rauch U, Bohrmann B, Kling D, Roqué M, Fallon JT, Badimon JJ, Himber J, Riederer MA and Nemerson Y: Blood-borne tissue factor: Another view of thrombosis. Proc Natl Acad Sci USA 96: 2311-2315, 1999.

21. Bogdanov VY, Balasubramanian V, Hathcock J, Vele O, Lieb M and Nemerson Y: Alternatively spliced human tissue factor: A circulating, soluble, thrombogenic protein. Nat Med 9: 458-462, 2003.

22. Szotowski B, Antoniak S, Poller W, Schultheiss HP and Rauch U: Procoagulant soluble tissue factor is released from endothelial cells in response to inflammatory cytokines. Circ Res 96: 1233-1239, 2005. 
23. Day SM, Reeve JL, Pedersen B, Farris DM, Myers DD, Im M, Wakefield TW, Mackman N and Fay WP: Macrovascular thrombosis is driven by tissue factor derived primarily from the blood vessel wall. Blood 105: 192-198, 2005.

24. Soejima H, Ogawa H, Yasue $H$, Kaikita K, Takazoe K, Nishiyama K Misumi K, Miyamoto S, Yoshimura M, Kugiyama K, et al: Angiotensin-converting enzyme inhibition reduces monocyte chemoattractant protein-1 and tissue factor levels in patients with myocardial infarction. J Am Coll Cardiol 34: 983-988, 1999.

25. Koh KK, Chung WJ, Ahn JY, Han SH, Kang WC, Seo YH, Ahn TH, Choi IS and Shin EK: Angiotensin II type 1 receptor blockers reduce tissue factor activity and plasminogen activator inhibitor type-1 antigen in hypertensive patients: A randomized, double-blind, placebo-controlled study. Atherosclerosis 177: $155-160,2004$.

26. Mälarstig A, Tenno T, Johnston N, Lagerqvist B, Axelsson T, Syvänen AC, Wallentin L and Siegbahn A: Genetic variations in the tissue factor gene are associated with clinical outcome in acute coronary syndrome and expression levels in human monocytes. Arterioscler Thromb Vasc Biol 25: 2667-2672, 2005.

27. Ott I, Koch W, von Beckerath N, de Waha R, Malawaniec A, Mehilli J, Schömig A and Kastrati A: Tissue factor promotor polymorphism-603 A/G is associated with myocardial infarction. Atherosclerosis 177: 189-191, 2004.

28. Pyo RT, Sato Y, Mackman N and Taubman MB: Mice deficient in tissue factor demonstrate attenuated intimal hyperplasia in response to vascular injury and decreased smooth muscle cell migration. Thromb Haemost 92: 451-458, 2004
29. Giannarelli C, Alique M, Rodriguez DT, Yang DK, Jeong D, Calcagno C, Hutter R, Millon A, Kovacic JC, Weber T, et al: Alternatively spliced tissue factor promotes plaque angiogenesis through the activation of hypoxia-inducible factor- $1 \alpha$ and vascular endothelial growth factor signaling. Circulation 130: 1274-1286, 2014.

30. Steffel J, Lüscher TF and Tanner FC: Tissue factor in cardiovascular diseases: Molecular mechanisms and clinical implications. Circulation 113: 722-731, 2006.

31. Mao S, Sun W and Kissel T: Chitosan-based formulations for delivery of DNA and siRNA. Adv Drug Deliv Rev 62: 12-27, 2010.

32. Zhang K, Qian Y, Wang H, Fan L, Huang C, Yin A and Mo X: Genipin-crosslinked silk fibroin/hydroxybutyl chitosan nanofibrous scaffolds for tissue-engineering application. J Biomed Mater Res A 95: 870-881, 2010.

33. Chen B, Dang J, Tan TL, Fang N, Chen WN, Leong KW and Chan V: Dynamics of smooth muscle cell deadhesion from thermosensitive hydroxybutyl chitosan. Biomaterials 28: 1503-1514, 2007.

34. Morris KV, Chan SW, Jacobsen SE and Looney DJ: Small interfering RNA-induced transcriptional gene silencing in human cells. Science 305: 1289-1292, 2004.

35. Ryther RC, Flynt AS, Phillips JA III and Patton JG: SiRNA therapeutics: Big potential from small RNAs. Gene Ther 12: 5-11, 2005.

36. Kanasty R, Dorkin JR, Vegas A and Anderson D: Delivery materials for siRNA therapeutics. Nat Mater 12: 967-977, 2013. 